\title{
A 5 Year Retrospective Study of Ovarian Tumours and Tumour-like Lesions in a Tertiary Referral Centre, Gandhi Medical College, Bhopal
}

\author{
Pramila Jain ${ }^{1}$, Reeni Malik², Varsha Rampuri ${ }^{3}$ \\ ${ }^{1}$ Department of Pathology, Gandhi Medical College, Bhopal, Madhya Pradesh, India. ${ }^{2}$ Department of Pathology, Gandhi \\ Medical College, Bhopal, Madhya Pradesh, India. ${ }^{3}$ Department of Pathology, Gandhi Medical College, Bhopal, Madhya \\ Pradesh, India.
}

\section{ABSTRACT}

\section{BACKGROUND}

Ovaries can be afflicted by various lesions, which can be non-neoplastic or neoplastic. Varied spectrum of clinical features and histopathological patterns are seen in these lesions. The present study was done to study the histopathological patterns of ovarian neoplastic and non-neoplastic lesions and their distribution in women of different age groups.

\section{METHODS}

This was retrospective study of all cases of neoplastic ovarian tumours, and nonneoplastic ovarian tumours including functional ovarian cysts received during 5year period from January 2014 to December 2018 in the Department of Pathology of Gandhi Medical College and Hamidia Hospital, Bhopal (M.P.). Data regarding age and tumour histopathology were recorded from pathology records. Routine H/E staining was performed.

\section{RESULTS}

A total of 541 different non-neoplastic and neoplastic lesions of ovaries were seen. Neoplastic tumours were more common $(350 ; 64.6 \%)$ than tumour-like lesions of the ovary $(191 ; 35.3 \%)$. Non neoplastic ovarian tumours were found to be more common than neoplastic ones in all age groups. Maximum number of ovarian tumours were seen in the age group of 21 - 50 years $(272,77.7 \%)$. Among tumourlike ovarian lesions, the most common were corpus luteal cysts $(75,13.8 \%)$. These were found to be more common in the age group of $31-50$ years $(123,65 \%)$. Surface epithelial tumours were the most common $(253,72.2 \%)$ followed by germ cell tumours $(70,12.9 \%)$.

\section{CONCLUSIONS}

Neoplastic tumours of ovaries are more common than tumour-like lesions of ovary. For all age groups, benign tumours are more common than malignant ones.

\section{KEY WORDS}

Ovarian Tumours, Ovarian Cysts
Corresponding Author: Dr. Varsha Rampuri, LIG 145, Bhartiniketan, Bhopal, Madhya Pradesh, India

E-mail: varsharampuri@gmail.com

DOI: $10.14260 /$ jemds $/ 2020 / 60$

Financial or Other Competing Interests: None.

How to Cite This Article: Jain P, Malik R, Rampuri V. A 5 year retrospective study of ovarian tumours and Tumour-like lesions in a tertiary referral centre, Gandhi Medical College, Bhopal. J. Evolution Med. Dent. Sci. 2020;9(05):266270, DOI: $10.14260 /$ jemds $/ 2020 / 60$

Submission 27-09-2019,

Peer Review 13-01-2020,

Acceptance 18-01-2020,

Published 03-02-2020. 


\section{BACKGROUND}

Ovaries can be afflicted by various lesions, which can be nonneoplastic or neoplastic. These lesions can be seen from the neonatal period to the post-menopausal period. Many of these ovarian lesions are functional ovarian cysts and they can be treated with minimal intervention.1,2 The prevalence of ovarian cysts and Tumour-like lesions has been reported to be between 2 to $4 \%$ among gynaecological admissions. ${ }^{3} \mathrm{~A}$ few of the benign lesions can be confused with neoplasm clinically, intraoperatively or on histopathological examination. ${ }^{4}$ Different cystic ovarian abnormalities needs to be differentiated with non-malignant features as histological abnormality decides proper treatment. Ovarian tumours represent the $6^{\text {th }}$ most common female cancer and the $4^{\text {th }}$ leading cause of death due to cancers in women. ${ }^{5}$ The pathology of ovarian tumours and Tumour-like conditions is one of the most complex areas in gynaecology. This is because the ovary gives rise to a great range and variety of tumours than any other organ in the body. The tissue from which the ovarian tumour arises is often uncertain and the mode of development of the presumptive tissue if often disputed. ${ }^{6}$

Ovary is projected as an important site of cancer in females by Indian Cancer Registry data. It comprises $8.7 \%$ of cancers in different parts of the country. ${ }^{7}$ Ovarian tumours have become an important cause of female gynaecological cancers which remain silent for a long time before they become symptomatic. They are important as they have large variety of neoplastic entities and also but because they are gradually increasing the mortality rate due to female genital cancers. $^{8}$

The aetiology of ovarian cancers is poorly understood. Previous epidemiological studies have focused on aetiology of epithelial tumours and classified them as factors with increased risk for ovarian cancers which include family history of ovarian cancer, advanced age, and nulliparity. Other factors that are considered as decreased risk for ovarian cancers are history of tubal ligation or hysterectomy, number of pregnancies, \& oral contraceptive (OC) use. There are certain Factors that have inconclusive relation to the occurrence of ovarian cancers are like smoking, consumption of alcohol or coffee, use of fertility and infertility drugs, Hormone Replacement Therapy (HRT), talc use, diet, obesity, age at first childbirth, age at menarche/menopause, breastfeeding. Whereas some studies have focused on aetiology of non-epithelial ovarian tumours have found that there is an increased risk of germ cell ovarian cancer occur among the mothers of whom were under 20 years of age at time of pregnancy, girls and young women, had a high pre pregnancy body mass or had used exogenous hormones during the pregnancy. whereas factors like history of oestrogen replacement therapy or oral contraceptives use was found to be associated with a decreased risk of developing sex cord-stromal ovarian tumours.9,10,11

Maximum cases of ovarian tumours are seen in women of child bearing age group of 20 and 45 years whereas most cases of neoplastic ovarian tumours are seen in older women between the ages of 45 and 65 years. ${ }^{12,13}$ Primary tumours are classified into surface epithelial tumours, germ cell tumours (both primitive germ cell and mature teratomas) and also monodermal like struma ovarii, sex cord stromal tumours like granulosa stromal cell and the comas. Surface epithelial tumours are most common. The laterality and stage of the tumour also indicates their nature for example, the sex cord stromal tumours are almost always confined to a single ovary. On the other hand, approximately $65 \%$ of the metastatic tumours are bilateral (Krukenberg). In this study, we have analysed the spectrum of ovarian tumours and their histopathological patterns. ${ }^{8}$

The present study was done to study the histopathological patterns of ovarian neoplastic and nonneoplastic lesions and their distribution in women of different age groups.

\section{METHODS}

This is retrospective study of all cases of functional ovarian cysts, benign ovarian neoplasms and ovarian cancer, received during 5-year period from January 2014 to December 2018 at pathology department of Gandhi Medical College and Hamidia Hospital, Bhopal (M.P.). Data regarding age and tumour histology were collected from medical records. Routine H/E staining was performed. The study was approved by Institute of Ethical Clearance and informed consent was obtained. Total number of different non neoplastic and neoplastic lesions of ovaries cases were counted from the histopathological records of pathology department. Age of the patient, histopathological type of ovarian lesion has been noted. And accordingly, percentage is been calculated.

\section{Statistical Analysis}

The data was collected and analysed using standard statistical chi - square test, $\mathrm{p}<0.05$ statistically significant. Data was entered in Microsoft excel and analysis was done using SPSS version 22.

\section{RESULTS}

A total of 541 different non neoplastic and neoplastic lesions of ovaries were seen. Neoplastic tumours were more common (350; 64.6\%) than Tumour-like lesions of ovary (191; $35.3 \%)$. Neoplastic tumours included, benign $(245 ; 70.0 \%)$ borderline/uncertain $(27 ; 7.7 \%)$ and malignant $(78 ; 22.2 \%)$ cases. (Tab no. 1) Surface epithelial tumours were most common $(253,72.2 \%)$ followed by germ cell tumours $(70$, $12.9 \%$ ) (Tab no. 4). Benign surface epithelial tumours comprised $55.6 \%(195 / 350)$ of all benign tumours whereas their malignant counterpart formed $13.05 \%$ (46/350) of all malignant tumours.

Tumour-like ovarian lesions included corpus luteal cysts $(75,13.8 \%)$, follicular cysts $(65,12.0 \%)$, twisted ovarian cysts $(30,5.54 \%)$, chocolate cyst/ Endometroid cyst (17, $3.1 \%)$, polycystic ovary $(02,0.36 \%)$, inflammatory $(02$, $0.36 \%$ ) (Tab no. 2). These are found to be more common in age group of $31-50$ years $(123,65 \%)$. (Tab no. 3 ) 
In this study, benign tumours are found more common than malignant ones, in all age groups. Most ovarian tumours were seen between the age group of 21 - 50 years (272, 77.7\%). (Table. 4). Among benign tumours, Surface epithelial tumours were found more common and accounted for $(253$, $72.02 \%$ ) of all ovarian tumours. Among these, widest range of age distribution was seen in cases of serous cystadenomas with youngest case of age 2 month and 4 month and oldest case was 85-year-old. Second most common tumours reported in this study are Germ cell tumours which constituted $19.87 \%$ of all ovarian tumours and seen mostly up to 50 year of age. Seven Metastatic tumours of ovary were found in age group ranging 21 - 70 years constituting $1.97 \%$. 01 case of undifferentiated tumour is reported in 55-year age of patient. (Tab no. 5).

\begin{tabular}{|c|c|}
\hline Type & Number (\%) \\
\hline Benign & $245(70 \%)$ \\
\hline Borderline/uncertain & $27(7.7 \%)$ \\
\hline Malignant & $78(22.2 \%)$ \\
\hline Total & $\mathbf{3 5 0}(\mathbf{1 0 0}) \%$ \\
\hline Table 1. Distribution of Ovarian Tumours (n = 350) \\
\hline
\end{tabular}

\begin{tabular}{|c|c|c|}
\hline Sl. No. & Histopathological Type & Number (\%) \\
\hline 1 & Corpus luteal cyst & $75(39.2 \%)$ \\
\hline 2 & Follicular cyst & $65(34.0 \%)$ \\
\hline 3 & Twisted ovarian cyst & $30(15.7 \%)$ \\
\hline 4 & Chocolate cyst (endometroid cyst) & $17(8.9 \%)$ \\
\hline 5 & Polycystic ovary & $02(1.0 \%)$ \\
\hline 6 & Inflammatory & $02(1.0 \%)$ \\
\hline \multicolumn{2}{|c|}{ Total } & $\mathbf{1 9 1}$ \\
\hline \multicolumn{2}{|c|}{ Table 2. Distribution of Tumour-like Lesions of the Ovary (n = 191) } \\
\hline
\end{tabular}

\begin{tabular}{|c|c|c|c|c|c|c|c|}
\hline 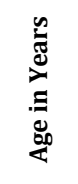 & 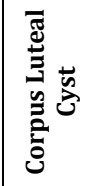 & 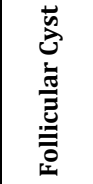 & 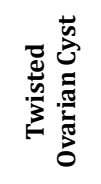 & 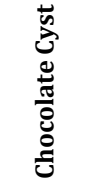 & 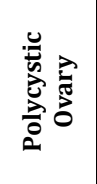 & 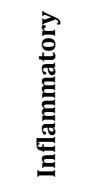 & 퓽 \\
\hline $0-10$ & 01 & 00 & 00 & 00 & 00 & 00 & $01(0.52 \%)$ \\
\hline $11-20$ & 06 & 02 & 04 & 00 & 00 & 00 & $12(7.0 \%)$ \\
\hline $21-30$ & 15 & 14 & 09 & 06 & 00 & 02 & $46(24.2 \%)$ \\
\hline $31-40$ & 26 & 28 & 06 & 07 & 01 & 00 & $68(36.0 \%)$ \\
\hline $41-50$ & 25 & 21 & 05 & 03 & 01 & 00 & $55(29.0 \%)$ \\
\hline $51-60$ & 02 & 00 & 05 & 00 & 00 & 00 & $07(3.2 \%)$ \\
\hline $61-70$ & 00 & 00 & 00 & 01 & 00 & 00 & $01(0.52 \%)$ \\
\hline $71-80$ & 00 & 00 & 01 & 00 & 00 & 00 & $01(0.52 \%)$ \\
\hline Total & $\begin{array}{c}75 \\
(39.2 \%) \\
\end{array}$ & \begin{tabular}{|c|}
65 \\
$(34.1 \%)$ \\
\end{tabular} & $\begin{array}{c}30 \\
(15.8 \%) \\
\end{array}$ & $\begin{array}{c}17 \\
(8.9 \%) \\
\end{array}$ & $\begin{array}{c}02 \\
(1.0 \%) \\
\end{array}$ & $\begin{array}{c}02 \\
(1.0 \%) \\
\end{array}$ & $\begin{array}{c}191 \\
(100 \%)\end{array}$ \\
\hline & le 3 & $\begin{array}{c}\text { stribu } \\
\text { Diffe }\end{array}$ & n of Tu & our-li & Lesions & fOva & \\
\hline
\end{tabular}

\begin{tabular}{|c|c|c|c|c|}
\hline $\begin{array}{c}\text { Age Group } \\
\text { (in yrs.) }\end{array}$ & $\begin{array}{c}\text { Benign } \\
(\mathbf{n = 2 4 5 )}\end{array}$ & $\begin{array}{c}\text { Borderline/ } \\
\text { Uncertain (n= 27) }\end{array}$ & $\begin{array}{c}\text { Malignant } \\
(\mathbf{n = 7 8 )}\end{array}$ & $\begin{array}{c}\text { Total } \\
(\mathbf{n = 3 5 0})\end{array}$ \\
\hline $0-10$ & $02(0.81 \%)$ & $01(3.7 \%)$ & $02(2.5 \%)$ & $05(1.4 \%)$ \\
\hline $11-20$ & $17(6.9 \%)$ & $03(11.1 \%)$ & $07(8.9 \%)$ & $27(7.7 \%)$ \\
\hline $21-30$ & $76(31.0 \%)$ & $05(18.5 \%)$ & $16(20.5 \%)$ & $97(27.7 \%)$ \\
\hline $31-40$ & $62(25.3 \%)$ & $05(18.5 \%)$ & $22(28.2 \%)$ & $89(25.4 \%)$ \\
\hline $41-50$ & $62(25.3 \%)$ & $09(33.3 \%)$ & $15(19.2 \%)$ & $86(24.5 \%)$ \\
\hline $51-60$ & $23(9.3 \%)$ & $02(7.4 \%)$ & $10(12.8 \%)$ & $35(10 \%)$ \\
\hline $61-70$ & $02(0.81 \%)$ & $02(7.4 \%)$ & $03(3.8 \%)$ & $07(2.0 \%)$ \\
\hline $71-80$ & $00(0.0 \%)$ & $00(0.0 \%)$ & $03(3.8 \%)$ & $03(0.85 \%)$ \\
\hline $81-90$ & $01(0.40 \%)$ & $00(0.0 \%)$ & $00(0.0 \%)$ & $01(0.28 \%)$ \\
\hline Total & $\mathbf{2 4 5 ( 1 0 0 \% )}$ & $\mathbf{2 7}(100 \%)$ & $\mathbf{7 8 ( 1 0 0 \% )}$ & $\mathbf{3 5 0}(\mathbf{1 0 0} \%)$ \\
\hline \multicolumn{5}{|c|}{ Table 4. Distribution of Ovarian Tumours in Various } \\
\hline \multicolumn{5}{|c|}{ Age Groups (n=350) } \\
\hline
\end{tabular}

\begin{tabular}{|l|c|c|c|c|c|c|}
\hline & & & & & \\
& & & & & \\
\end{tabular}

\section{DISCUSSION}

Ovarian neoplasm is the very interesting tumour of the women in terms of histogenesis, clinical behaviour and malignant potentiality. Many of the ovarian neoplasm cannot be detected early in their development, they account for a disproportionate number of fatal cancers, being responsible for almost half of deaths from cancer of female genital tract. ${ }^{14}$ Histomorphological classification of ovarian tumours forms an integral part of the evaluation of the neoplasms. ${ }^{15}$

In present study total 541 cases of ovarian lesions were studied. Out of which $64.6 \%$ (350) cases were of ovarian tumours and $191(35.3 \%)$ cases were of ovarian Tumour-like lesions. Main aspects considered in this study were histopathological types and frequency of different histopathological types of ovarian tumours and Tumour-like lesions in different age groups.

Functional ovarian cysts are common in women of reproductive age group, but rare after menopause. It can occur at any age including the fetus (in uterus). These Ovarian cysts can act as an indicator of any hidden malignant transformation. Surgery becomes essential, when these ovarian cysts increase in size, continue to exist over prolonged period or becomes extremely painful.1,2 Two types of functional ovarian cysts may develop: follicular cysts and corpus luteum cysts. Follicular cysts occurring in the first 2 weeks of the cycle, are formed when egg is not released from ovarian sac and sac fills and swells up with fluid whereas corpus luteal cysts occur in the latter half of the cycle and are formed when the egg is released from the ovarian sac and after which it closes and fills and swells up with fluid. These cysts may become inflamed or can bleed without apparent external cause or stimulus, producing symptoms. Other cysts include endometrial cysts, which are formed when the endometrial tissue gets to the ovaries, these cysts are filled with blood.1,2 In the present study, the patients were of all ages. In present study these cysts were seen in the age group from 2 years to 80 years. Ovarian cysts requiring surgeries, two third of them were found to be functional ovarian cysts, as shown in a study by Eriksson et al quoted by De Kroon et al. ${ }^{16}$ 
Luteal and Follicular cysts were the most commonly diagnosed cysts. This is similar to a study from India, ${ }^{17}$ Tayyiaba et al ${ }^{18}$ and Choi et al. ${ }^{19}$ The tumours were seen in the age group from 2 month to 85 years, with maximum number of cases in $21-30$ years, $27.7 \%$ followed by $31-40$ years, $25.4 \%$. Similar observations were made by Saxena et al and Jagadeshwari et al. About $95 \%$ of these tumours have been found to be benign. Ovarian malignancies represent the greatest clinical challenge of all the gynaecological malignancies. During the reproductive years most of the ovarian tumours encountered in this group only. The chance that an ovarian tumour is malignant in a patient younger than 45 years is 1 in $15 .^{3}$

Maximum cases of benign ovarian tumours were seen in $3^{\text {rd }}$ and $4^{\text {th }}$ decade with mean age of 30.7 years. Malignant neoplasms were expectedly seen with advancing age peaking in $4^{\text {th }}$ decade of life with mean age of presentation being 37.5 years. Among surface epithelial tumours, maximum cases i.e., $39.7 \%$ of benign serous tumours along with serous cysts were found. Mature teratoma and mucinous cysts were second commonest ovarian lesions each constituting $12.9 \%$. However, teratoma is found to be commonest benign ovarian neoplasm in a study by Ong et al. We found no case of benign endometroid tumour. As benign endometroid tumours are rare in occurrence as compared to benign serous and mucinous tumours.

In our study $72.2 \%$ epithelial tumours were diagnosed with 46 cases of malignant epithelial tumours accounting for $13.1 \%$ of all malignant neoplasms. Kooning et al found that epithelial tumours represent $60 \%$ of all ovarian neoplasm and $85 \%$ of malignant ovarian neoplasm. Bushra et al reported 96\% epithelial tumours in her series. Prevalence of Epithelial tumours of ovary increases with age with peak seen in third and fourth decades of life, but they are rare in children. In this study most of the epithelial tumours are seen in third and fourth decades. We found 02 cases of epithelial neoplasm in first decade and 13 cases in second decade.

Borderline tumours of ovary also called as tumours of low malignant potential. Their onset is at relatively early age and they have a favourable prognosis. They comprise $4 \%-14 \%$ of all epithelial ovarian neoplasms. In this study, 03 cases of borderline serous papillary neoplasm (0.85\%) were diagnosed. In present study, serous cystadenocarcinoma $(8.5 \%)$ was the commonest malignant epithelial neoplasm closely followed by mucinous cystadenocarcinoma (3.4\%).

Endometroid carcinoma of ovaries is most common tumour to be associated with endometriosis. They constitute $10-15 \%$ of all ovarian cancers. Out of these about $15-30 \%$ occur at the same time with endometrial carcinoma. This is in contrast to our study as only $0.57 \%$ endometroid carcinoma were diagnosed. Clear cell carcinomas of ovary constitute approximately $5 \%$ of ovarian carcinomas. In our study only 01 case of clear cell carcinoma is seen in a 35-year-old female. Brenner tumour of ovary comprise about $2-3 \%$ of ovarian tumours and are rarely malignant. We found 03 cases with two benign and one malignant. Germ cell tumours of ovary are the second most common group of ovarian neoplasms. They constitute $15-20 \%$ of all ovarian tumours. Among all the germ cell tumours, the most common lesion in this group is mature teratoma and it is the only benign tumour in this group. Similar findings are seen in our study. Rest other germ cell tumours are malignant and account for $6 \%$ of malignant ovarian tumours. Rare ovarian tumours include Dysgerminomas constitute $2 \%$ of all ovarian tumours. They occur predominantly in young women. This tumour is the ovarian counterpart of seminoma of the testis. In our study dysgerminomas comprise $1.1 \%$ of all ovarian tumours.

\section{CONCLUSIONS}

Ovarian cysts and masses show a wide morphological diversity and therefore pose many challenges. Proper histological examination is the best way to exclude malignancy, but this requires surgery. Routinely stained slides are evaluated to make a specific diagnosis, but much less often. In developed countries, recent improvement in patient survival is attributed to diagnosis at an early stage. ${ }^{20}$ Symptoms of ovarian tumours are vague and insidious; therefore, they are often difficult to detect until they are advanced in stage or size. Identification of their various histologic patterns is essential to make diagnosis and assess prognosis of ovarian tumours. In this study, non-neoplastic ovarian tumours were found to be more common than neoplastic ones across all age groups. Among various ovarian tumours, surface epithelial tumours were the most common histopathological type of ovarian tumour. Among rare malignant ovarian tumours, one of them is endodermal sinus tumour, also known as yolk sac tumour, and usually occurs in $2^{\text {nd }}$ decade of life. Similar findings are seen in our studies. Another ovarian tumour of interest is sex cord stromal tumours seen in all age groups and comprise approximately of $8 \%$ of ovarian tumours. These tumours are fascinating as they have hormonal effects which are rare in other ovarian neoplasms. Granulosa cell tumour of ovary is considered as the most common malignant sex cord stromal tumour and it is also the most common ovarian tumour that produces oestrogen. Adult granulosa cell tumours are far more common than the juvenile type. They are most commonly seen in peri- and post-menopausal women. This is consistent to findings of our study.

\section{REFERENCES}

[1] Grimes DA, Jones LB, Lopez LM, et al. Oral contraceptives for functional ovarian cysts. Cochrane Database Syst Rev 2006;4:CD006134.

[2] Holt VL, Cushing-Haugen KL, Daling JR. Risk of functional ovarian cyst: effects of smoking and marijuana use according to body mass index. Am J Epidemiol 2005;161(6):520-5.

[3] Berek JS. Berek and Novak's gynaecology. 15th edn. Lippincott Williams \& Wilkins 2011.

[4] Clement PB. Selected miscellaneous ovarian lesions: small cell carcinomas, mesothelial lesions, mesenchymal and mixed neoplasms, and non-neoplastic lesions. Mod Pathol 2005;18 Suppl 2:S113-29.

[5] Tortolero-Luna G, Mitchell MF, Rhodes-Morris HE. Epidemiology and screening of ovarian cancer. Obstet Gynecol Clin North Am 1994;21(1):1-23. 
[6] Kumar P, Malhotra N. Jeffcoate's principles of gynaecology. $7^{\text {th }}$ edn. Jaypee Brothers Medical Publishers (P) Ltd 2008.

[7] Murthy NS, Shalini S, Suman G, et al. Changing trends in incidence of ovarian cancer - the Indian scenario. Asian Pac J Cancer Prev 2009;10(6):1025-30.

[8] Valson H, Arakeri S, Davis DM, et al. Retrospective study of Tumour-like conditions of ovary from a rural hospital in Kerala. Int J Reprod Contracept Obstet Gynecol 2017;6(8):3275-9.

[9] Jung SE, Lee JM, Rha SE, et al. CT and MR imaging of ovarian tumours with emphasis on differential diagnosis. Radiographics 2002;22(6):1305-25.

[10] Ness RB, Grisso JA, Cottreau C, et al. Factors related to inflammation of the ovarian epithelium and risk of ovarian cancer. Epidemiology 2000;11(2):111-7.

[11]Zhang J, Ugnat AM, Clarke K, et al. Ovarian cancer histology specific incidence trends in Canada 1969-1993: age-period-cohort analyses. Br J Cancer 1999;81(1):1528.

[12] Day NE, Krishnan E. Epidemilogy of gynaecological cancers. In: Shaw RW, Souter P, Stanton SL, eds. Gynaecology. $2^{\text {nd }}$ edn. Edinburgh: Churchill Living Stone 1997;477-87.
[13] Ellenson LH, Pirog EC. The female genital tract. Chap- 22. In: Robbins SL, Kumar V, Cortan RS, eds. Robbins and Cotran pathologic basis of disease. $8^{\text {th }}$ edn. Philadelphia, PA: Saunders/Elsevier 2010:1005-63.

[14] Tavassoli FA, Devilee P, eds. World Health Organization classification of tumours. Pathology and genetics: tumours of the breast and female genital organs. Lyons, France: IARC Press 2003.

[15] Saxena MHK, Devi G, Prakash P, et al. Ovarian neoplasms- a retrospective study of 356 cases. J Obstret Fynec India 1980;30:522-7.

[16] de Kroon CD, van der Sandt HA, van Houwelingen JC, et al. Sonographic assessment of non-malignant ovarian cysts: does sonohistology exists? Hum Reprod 2004;19(9):2138-43.

[17] Gupta N, Bisht D, Agarwal AK, et al. Retrospective and prospective study of ovarian tumours and Tumour-like lesions. Indian J Pathol Microbiol 2007;50(3):525-7.

[18] Wasim T, Majrroh A, Siddiq S. Comparison of clinical presentation of benign and malignant ovarian tumours. J Pak Med Assoc 2009;59(1):18-21.

[19] Choi HJ, Kim SH, Kim HC, et al. Ruptured corpus luteal cyst: CT findings. Korean J Radiol 2003;4(1):42-5.

[20] Coleman MP, Esteve J, Damiecki P. Trends in cancer incidence and mortality. IARC Sci Publ 1993;(121):1806. 